\title{
Erratum to: Mapping sediment thickness of Islamabad city using empirical relationships: Implications for seismic hazard assessment
}

\author{
SARFRAZ KHAN and M AsIF KHAN
}

J. Earth Syst. Sci., doi:10.1007/s12040-016-0675-0, 125(3), pp. 623-644

In the original version of this article, which appeared in Journal of Earth System Science 125(3) 623-644, figures 1 and 2 were incorrectly presented. The corrected figures are as follows.

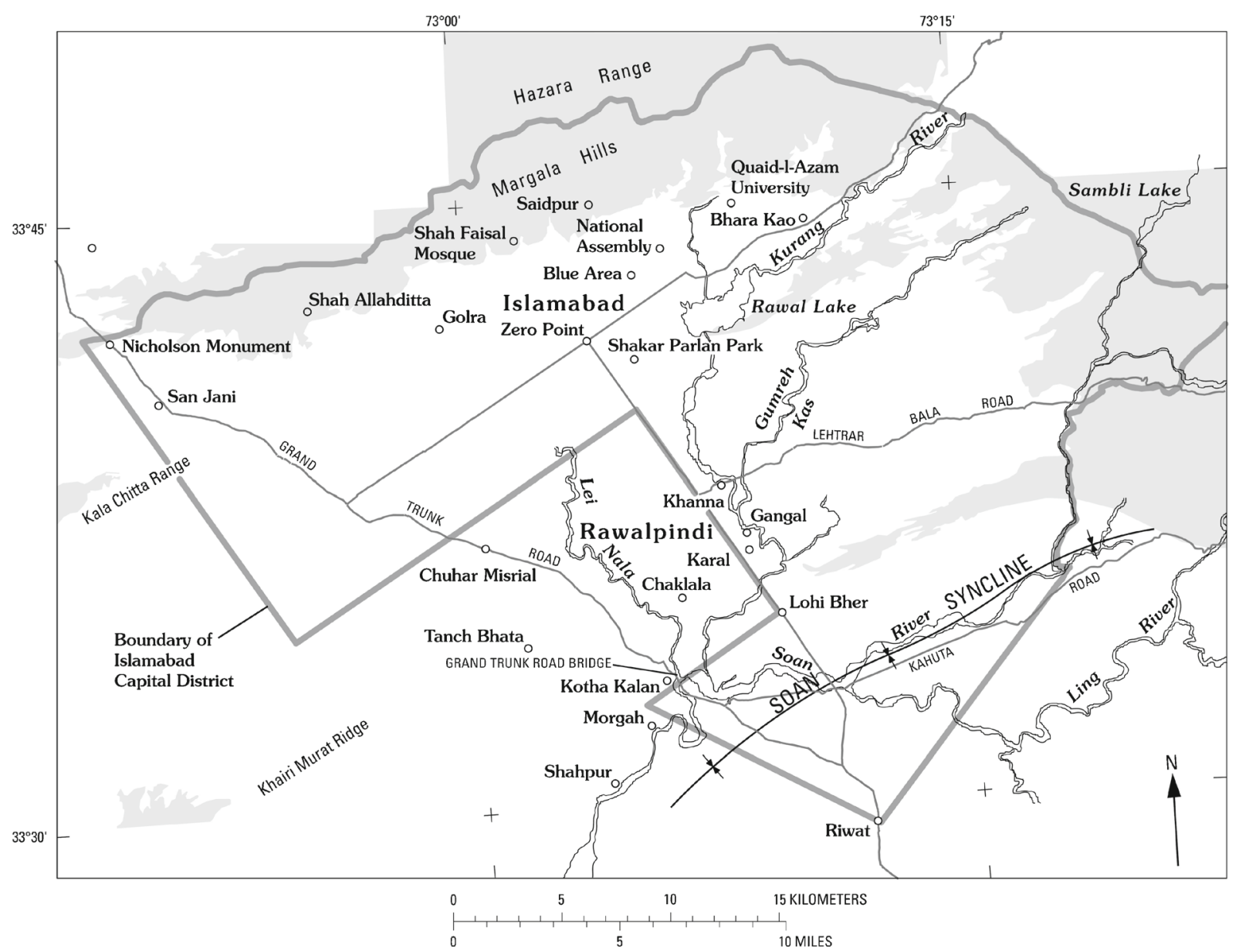

Figure 1. Location map of the study area, the bold light grey line shows the boundary of the Islamabad region.

\footnotetext{
*The online version of the original article can be found at http://dx.doi.org/10.1007/s12040-016-0675-0
}

J. Earth Syst. Sci., DOI 10.1007/s12040-016-0712-z, 125, No. 4, June 2016, pp. 897-898

(C) Indian Academy of Sciences 


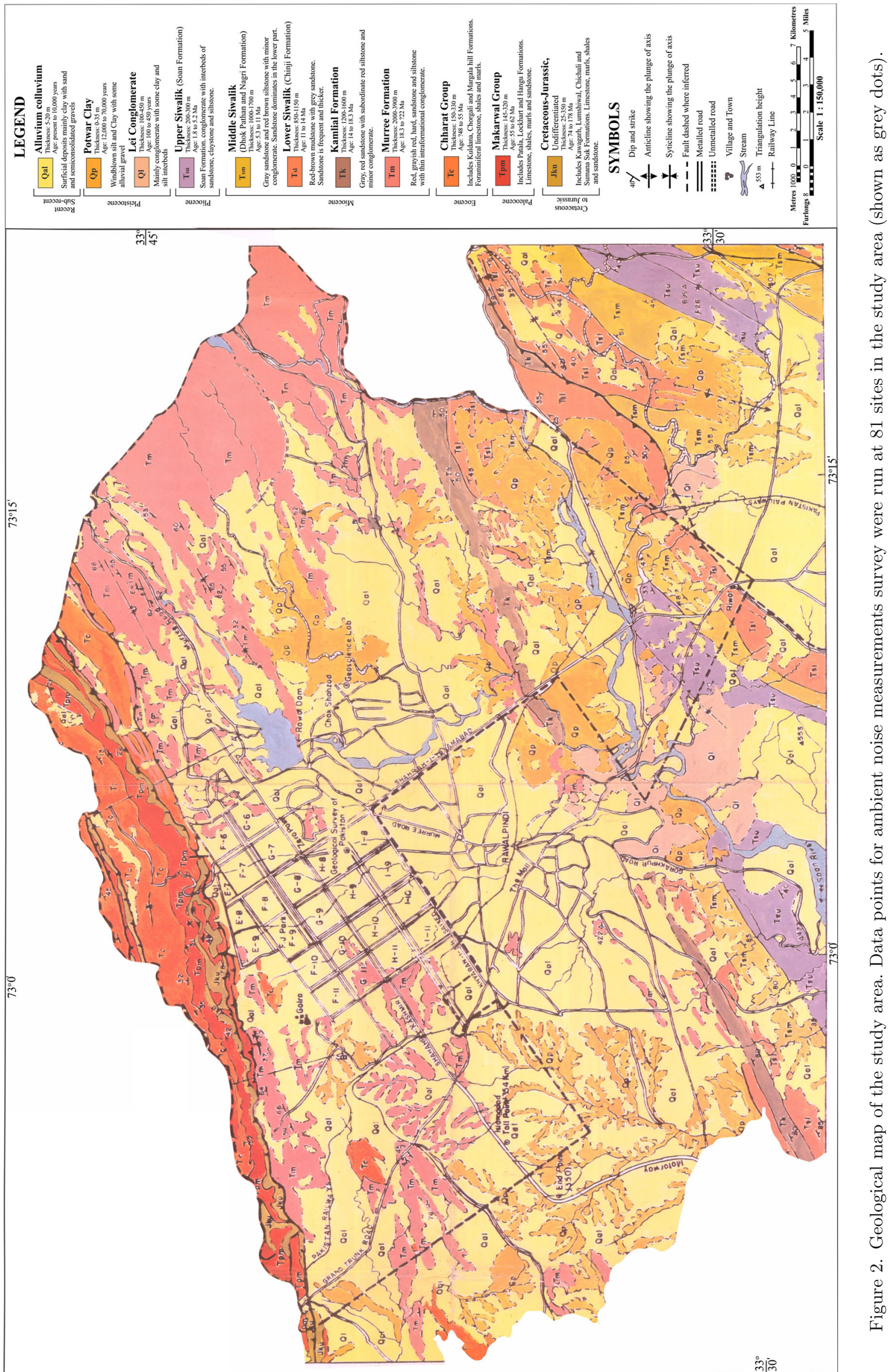

